\title{
Biochemical characterisation, enteropathogenicity and antimicrobial resistance plasmids of clinical and environmental Aeromonas isolates
}

\author{
A. CHAUDHURY, G. NATH, B. N. SHUKLA and S. C. SANYAL*
}

Department of Microbiology, Institute of Medical Sciences, Banaras Hindu University, Varanasi 221 005, India

\begin{abstract}
One hundred and eight strains of Aeromonas from clinical and environmental samples were speciated. Seven species were identified, the most prevalent of which was $A$. hydrophila. Experimental studies in an animal model with 36 representative strains of different species revealed that all strains could cause significant fluid accumulation in rabbit ileal loops. Of 107 strains showing single or multiple antimicrobial resistance, the highest incidence of resistance was shown for $\beta$-lactam antibiotics other than cefotaxime. Transferable resistance plasmids, encoding resistance to ampicillin, cephalexin, cefoxitin, erythromycin and furazolidone, either alone or in combination, were detected in 35 strains. A further proportion of strains could be cured of one or more resistance markers, including resistance to nalidixic acid, and this was accompanied by the loss of plasmid DNA. The plasmids ranged in size between 85.6 and $>150 \mathrm{~kb}$.
\end{abstract}

\section{Introduction}

The genus Aeromonas has come into prominence in the last two decades, not only for its role as an enteropathogen, but also as the aetiological agent in several extra-intestinal infections culminating sometimes into life-threatening conditions such as meningitis and septicaemia [1]. Extensive taxonomic studies over the last 8 years have proposed at least 10 species of Aeromonas, of which three (A. salmonicida, $A$. eucrenophila and $A$. media) are psychrophilic and nonpathogenic to man. Enteropathogenicity of Aeromonas in an experimental animal model was first reported from this laboratory [2] and the virulence potential of three Aeromonas spp. (A. hydrophila, $A$. caviae and $A$. sobria) has been compared [3]. Since this study there has been no report assessing which species of Aeromonas is more virulent, particularly among the new species. Drug resistance in Aeromonas species is well known. Although antimicrobial susceptibilities of clinical $[4,5]$ and environmental $[6,7]$ isolates have been reported, most of the studies have involved relatively few strains and no comparative study of antimicrobial resistance between these two populations of isolates has been made so far. Furthermore, the genetic basis of antimicrobial resistance in Aeromonas spp. is still poorly understood $[8,9]$. This study, determined the biochemical character and antimicrobial resistance patterns of Aeromonas isolates from both clinical and environmental sources (fresh water iso-

Received 6 Jan. 1995; revised version accepted 1 Nov. 1995.

${ }^{*}$ Correspondence should be sent to Professor S. C. Sanyal. lates). Representative strains of each species were examined for enteropathogenicity and the presence of resistance plasmids (R-plasmids).

\section{Materials and methods}

\section{Bacterial strains}

A total of 108 strains of Aeromonas, comprising 52 clinical and 56 environmental isolates were examined. The strains were isolated on antibiotic-free media over a period of 15 years from diarrhoeal patients and from the River Ganges at Varanasi, respectively, and had been maintained in peptone agar stab cultures at room temperature. Only those strains which were gramnegative rods, motile, oxidase positive, glucose fermenting (with or without gas) and resistant to vibriostatic agent $0 / 129$, at $150-\mu$ g disk concentration, were considered as belonging to the genus Aeromonas [10]. Isolates were speciated according to the scheme of Carnahan et al. [11].

\section{Enteropathogenicity test}

Live cells of 36 representative strains of the various species of Aeromonas, from both clinical and environmental sources, were tested for enteropathogenicity in Belgian strains of adult albino rabbits following standard methods [12] with slight modification [13]. Briefly, the strains were grown in Brain Heart Infusion Broth (BHIB) (Difco) for $3 \mathrm{~h}$, diluted 10-fold in the same medium and inoculated into rabbit ileal loops in doses of $1.0 \mathrm{ml}$ containing $10^{4}-10^{5} \mathrm{cfu}$. The toxigenic 
Vibrio cholerae strain 569B grown in BHIB, and unseeded BHIB, served as positive and negative controls, respectively. Each strain was tested in duplicate. Consecutive passages of the strains that caused little or no fluid accumulation in initial experiments were made in rabbit ileal loops until a good positive response was obtained.

\section{Antimicrobial susceptibility}

Overnight nutrient broth cultures of the control (Staphylococcus aureus NCTC 6571) and test strains were diluted in phosphate-buffered saline $(\mathrm{pH} 7.4)$ to a concentration of $c .10^{4}-10^{5} \mathrm{cfu} / \mathrm{ml}$. The antimicrobial susceptibility of each isolate was determined by Stokes' disk diffusion technique and the criteria for defining resistance were those described previously [14]. The minimum inhibitory concentration (MIC) of each antimicrobial agent was determined by inoculation of diluted overnight cultures of each isolate on to Mueller-Hinton agar (Difco) containing doubling dilutions of the drugs $(5-1280 \mathrm{mg} / \mathrm{L})$.

\section{Transfer of drug resistance}

Resistant Aeromonas strains were incubated in mixed culture for $18 \mathrm{~h}$ with mutant Escherichia coli K12 recipient strains resistant to either nalidixic acid or rifampicin to allow conjugation, following the method of Anderson and Lewis [15]. Strains that failed to show any direct transfer of resistance markers were re-tested for mobilisation of non-conjugative plasmids in triparental matings with $E$. coli $\mathrm{K} 12\left(\mathrm{X}^{+}\right)$[16]. Transfer frequencies of resistance markers were calculated as the ratio of resistant recipients (transconjugates) to total recipients.

\section{Curing}

Strains that failed to show any transfer of resistance markers were examined for the loss of resistance phenotypes by curing with ethidium bromide (EB) at subinhibitory concentrations or SDS $10 \mathrm{~g} / \mathrm{L}$. Overnight cultures grown in the presence of the curing agent were plated on nutrient agar to obtain individual colonies which were then replica plated on to antibioticcontaining media to detect those clones that had been cured of the resistance phenotype.

\section{Plasmid extraction and detection}

Plasmid DNA was isolated by the method of Kado and Liu [17] and separated by horizontal electrophoresis at $150 \mathrm{~V}, 110 \mathrm{~mA}$ for $5 \mathrm{~h}$ in agarose (Sigma) $0.7 \%$ gels prepared with Tris acetate buffer $(40 \mathrm{mM}$ Tris, $2 \mathrm{mM}$ sodium acetate; $\mathrm{pH}$ 7.9). Gels were stained with ethidium bromide solution $(0.5 \mu \mathrm{g} / \mathrm{ml})$ for $2 \mathrm{~h}$ and plasmid bands were visualised with an ultra-violet transilluminator and photographed with a $23 \mathrm{~A}$ Wratten filter. Plasmids extracted from reference $E$. coli strains
V517 $(53.7-2.1 \mathrm{~kb})$ and $E$. coli $(\mathrm{R} 1)(90 \mathrm{~kb})$ served as markers in electrophoresis.

\section{Results and discussion}

Seven different Aeromonas species were identified amongst the total of 108 strains. A. hydrophila was the most frequently isolated species $(40.7 \%)$ followed by A. caviae $(32.4 \%)$. There was no significant difference in the prevalence of these two species between environmental and clinical isolates. A total of 23 isolates $(21.3 \%)$ were characterised as $A$. veronii (11.1\% biovar sobria and $10.2 \%$ biovar veronii) and this species was more common amongst environmental isolates $(13.9 \%)$. The remaining six strains comprised A. jandaei (3.7\%), A. schubertii (0.9\%) and A. trota $(0.9 \%)$.

The results of animal model studies showed that each of 36 representative strains of Aeromonas, regardless of their species designation or source of isolation, caused significant fluid accumulation $(0.88-1.5 \mathrm{ml} / \mathrm{cm}$ of rabbit gut) either in initial experiments or after consecutive passages through rabbit gut. This indicates that both environmental and clinical isolates are potentially enteropathogenic. Greater fluid accumulation in rabbit gut was caused by $A$. hydrophila and $A$. veronii biovar sobria than by other species of the genus and this may reflect the greater diarrhoeagenic potential of these two species. The ability of $A$. jandaei and $A$. trota to cause fluid accumulation only after consecutive passage may indicate the potential enteropathogenicity of these strains, which in turn may be due to a mechanism of repression and derepression in the toxin gene [18].

In this study, 107 of the 108 strains examined were resistant to one or more antimicrobial agents as determined by Stokes' disk diffusion method. All strains found to be susceptible or of intermediate susceptibility by Stokes' method were inhibited by the corresponding agent at the arbitrary breakpoint of $5 \mathrm{mg} / \mathrm{L}$. Hence, in this study, strains inhibited by $5 \mathrm{mg} / \mathrm{L}$ were classed as susceptible and those that grew were considered to be resistant. Resistance was observed most commonly to ampicillin (88.9\%) followed by cephalexin (75\%), cephalothin (73.2\%), erythromycin (61.1\%) and cefoxitin (35.2\%). Relatively few strains were resistant to furazolidone (25\%), nalidixic acid (14.8\%), trimethoprim (9.3\%) and chloramphenicol $(1.8 \%)$. All the strains were susceptible to tetracycline, aminoglycosides (neomycin and gentamicin), cefotaxime and ciprofloxacin. When individual species were examined, resistance to cephalexin was appreciably higher in $A$. veronii biovar veronii $(72.2 \%)$ than in biovar sobria $(25 \%)$. In addition to the single ampicillin-sensitive strain of $A$. trota, seven strains of $A$. caviae, two of $A$. hydrophila and one each of $A$. veronii biovar veronii and $A$. 
schubertii were also susceptible to ampicillin. Although ampicillin susceptibility is characteristic for A. trota, the finding that other Aeromonas spp. particularly $A$. caviae, were susceptible to this agent is significant and supports earlier reports regarding the presence of a small but definite number of ampicillinsusceptible aeromonads [6]. However, the finding in this study that all the Aeromonas strains tested were susceptible to tetracycline is in direct contrast with earlier reports on tetracycline susceptibility of this genus [7]. Furthermore, only two strains showed chloramphenicol resistance of low level and these findings may reflect the marked reduction in the use of these drugs.

Overall, these data suggest that identification of Aeromonas isolates to species level may be important for the instigation of appropriate chemotherapy. As aminoglycosides, chloramphenicol, ciprofloxacin and cefotaxime have all shown excellent activity against the aeromonads in this study, these agents may be considered as the drugs of choice in extra-intestinal infections, especially in immunocompromised patients, and in severe protracted diarrhoeal diseases. The similarity in pattern and frequency of antibiotic resistance of environmental and human isolates reflects the increasing use of antimicrobial agents and chemicals in agriculture and animal farms.

Twenty-five (23.4\%) of 107 resistant Aeromonas isolates could transfer either all or some of their resistance markers to recipient $E$. coli $\mathrm{K} 12$ strains and a further 10 strains could do so following mobilisa- tion. No significant difference was observed in transfer pattern and frequency $\left(10^{-5}-10^{-7}\right)$ between the experiments carried out at $37^{\circ} \mathrm{C}$ and $28^{\circ} \mathrm{C}$. Of the 72 isolates for which no conjugative or mobilisable Rplasmids were detected, 45 could be cured of one or more of their resistance markers. Comparative analysis of the plasmid DNA content of 15 original isolates and their cured derivatives confirmed that loss of resistance phenotype was accompanied by loss of plasmid DNA. The size of plasmids characterised in this study ranged between $85.6 \mathrm{~kb}$ and $>150 \mathrm{~kb}$ (Table 1).

Ampicillin resistance, either singly or in combination, was transferable from five strains only, but could be cured from a further 17 strains indicating that ampicillin resistance may be encoded not only by chromosomal DNA but also by plasmids. A single plasmid of $105.9 \mathrm{~kb}$ was detected in strains having ampicillin resistance as the sole resistance marker, while molecular sizes of plasmids ranged from 85.6 to $>150 \mathrm{~kb}$ in strains with additional resistance markers. A conjugative ampicillin-resistance plasmid of $110 \mathrm{Mda}$ has been demonstrated previously in a multiresistant Aeromonas isolate of Indian origin [19].

In the present study, transferable plasmids ranged in size between $85.6 \mathrm{~kb}$ and $>150 \mathrm{~kb}$ and conferred resistance to up to four different antibiotics. Borrego et al. [8] have suggested that resistance to nalidixic acid may be linked to genes carried by plasmids as well as chromosomal genes in Aeromonas spp. The nalidixic acid resistance marker in the Aeromonas

Table 1. Characteristics of Aeromonas R-plasmids in representative strains

\begin{tabular}{|c|c|c|c|c|}
\hline Species & $\begin{array}{c}\text { Strain } \\
\text { no. }\end{array}$ & $\begin{array}{l}\text { Resistance } \\
\text { markers }\end{array}$ & $\begin{array}{l}\text { Type of } \\
\text { plasmid }\end{array}$ & $\begin{array}{l}\text { Plasmid } \\
\text { size }(\mathbf{k b})\end{array}$ \\
\hline A. hydrophila & $\begin{array}{r}30 \\
37 \\
54 \\
75 \\
78 \\
106\end{array}$ & $\begin{array}{l}\text { AmENaCpChCnF } \\
\text { AmENaFCpCh } \\
\text { AmFCpChCnE } \\
\overline{\text { AmECp }} \\
\text { AmCpChENa } \\
\text { AmCpCh } \underline{\text { InE }}\end{array}$ & $\begin{array}{l}\text { Curable } \\
\text { Curable } \\
\text { Transferable } \\
\text { Transferable } \\
\text { Curable } \\
\text { Curable }\end{array}$ & $\begin{array}{l}103.2 \\
103.2 \\
85.6,>150 \\
100 \\
94.8 \\
100\end{array}$ \\
\hline A. caviae & $\begin{array}{r}1 \\
5 \\
19 \\
45 \\
57 \\
62 \\
66 \\
92 \\
100\end{array}$ & $\begin{array}{l}\text { AmE } \\
\text { Am } \bar{E} \mathrm{Ep} \\
\text { AmCpCn } \\
\overline{\text { AmEFCpCh }} \\
\text { AmTpECpCn } \\
\text { AmCpChCnE } \\
\text { AmENaChCpF } \\
\text { AmNaChCn } \\
\text { CpChEn }\end{array}$ & $\begin{array}{l}\text { Transferable } \\
\text { Transferable } \\
\text { Transferable } \\
\text { Curable } \\
\text { Transferable } \\
\text { Transferable } \\
\text { Curable } \\
\text { Curable } \\
\text { Curable }\end{array}$ & $\begin{array}{l}96 \\
90 \\
96 \\
96 \\
90 \\
90,>150 \\
94.8,>150 \\
90 \\
85.6\end{array}$ \\
\hline A. veronii biovar veronii & $\begin{array}{r}23 \\
24 \\
76 \\
104\end{array}$ & $\begin{array}{l}\frac{\mathrm{AmECp}}{\mathrm{AmE}} \\
\frac{\mathrm{Am}}{\underline{\mathrm{Am}}}\end{array}$ & $\begin{array}{l}\text { Curable } \\
\text { Curable } \\
\text { Curable } \\
\text { Curable }\end{array}$ & $\begin{array}{l}96 \\
110.5 \\
105.9 \\
105.9\end{array}$ \\
\hline A. veronii biovar sobria & 14 & $\mathrm{AmNaCp}$ & Curable & 144 \\
\hline $\begin{array}{l}\text { A. jandaei } \\
\text { A. schubertii }\end{array}$ & $\begin{array}{l}31 \\
81\end{array}$ & $\begin{array}{l}\mathrm{AmNaFChCpCn} \\
\mathrm{AmNa}\end{array}$ & $\begin{array}{l}\text { Curable } \\
\text { Curable }\end{array}$ & $\begin{array}{l}96,>150 \\
94.8\end{array}$ \\
\hline
\end{tabular}

Underlining indicates transferable or curable resistance markers. Am, ampicillin; $\mathrm{Cp}$, cephalexin; $\mathrm{Ch}$, cephalothin; $\mathrm{Cn}$, cefoxitin; $\mathrm{E}$, erythromycin; $\mathrm{F}$, furazolidone; $\mathrm{Na}$, nalidixic acid. 
strains studied here was not-transferable but could be cured in $50 \%$ of strains. Loss of the nalidixic acid resistance phenotype from these strains was accompanied by loss of plasmids ranging in size from 94.8 to $>150 \mathrm{~kb}$, suggesting that nalidixic acid resistance is linked to plasmid DNA, at least in some strains.

This study highlights the potential pathogenicity and growing incidence of multiresistance within clinical and environmental isolates of Aeromonas. The increasing use of antibiotics in the human population, animal husbandry and pisciculture have provided an intense selection pressure for the genes coding antimicrobial resistance in soil and aquatic microorganisms. Moreover, the aquatic and gut bacteria come in frequent intimate contact with other organisms bearing transferable R-plasmids and these complex interactions in nature are likely to be contributing to the emergence of multi-drug-resistance Aeromonas spp.

\section{References}

1. Altwegg M, Geiss HK. Aeromonas as a human pathogen. CRC Crit Rev Microbiol 1989; 16: 253-286.

2. Sanyal SC, Singh SJ, Sen PC. Enteropathogenicity of Aeromonas hydrophila and Plesiomonas shigelloides. J Med Microbiol 1975; 8: 195-198.

3. Janda JM, Clerk RB, Brenden R. Virulence of Aeromonas species as assessed through mouse lethality studies. Curr Microbiol 1985; 12: 163.

4. Motyl MR, McKinley G, Janda JM. In vitro susceptibilities of Aeromonas hydrophila, Aeromonas sobria, and Aeromonas caviae to 22 antimicrobial agents. Antimicrob Agents Chemother 1985; 28: 151-153.

5. Kuijpers EJ, Peeters MF, Schoenmakers BSC, Zanen HC.
Antimicrobial susceptibility of sixty human fecal isolates of Aeromonas species. Eur J Clin Microbiol Infect Dis 1989; 8: 248-250.

6. Richardson CJL, Robinson JO, Wagener LB, Burke V. In-vitro susceptibility of Aeromonas spp. to antimicrobial agents. $J$ Antimicrob Chemother 1982; 9: 267-274.

7. Rahim Z, Sanyal SC, Aziz KMS, Huq MI, Chowdhury AA. Isolation of enterotoxigenic, hemolytic and antibiotic-resistant Aeromonas hydrophila strains from infected fish in Bangladesh. Appl Environ Microbiol 1984; 48: 865-867.

8. Borrego JJ, Moriñigo MA, Martinez-Manzanares E et al. Plasmid associated virulence properties of environmental isolates of Aeromonas hydrophila. J Med Microbiol 1991; 35: 264-269.

9. Hedges RW, Smith P, Brazil G. Resistance plasmids of aeromonads. J Gen Microbiol 1985; 131: 2091-2095.

10. Popoff M. Genus III. Aeromonas. Kluyver and Van Niel 1936 In: Kreig NR, Holt JG (eds) Bergey's Manual of systematic bacteriology. Baltimore, Williams and Wilkins. 1984. 545-548.

11. Carnahan AM, Behram S, Joseph SW. Aerokey II: a flexible key for identifying clinical Aeromonas species. $J$ Clin Microbiol 1991; 29: 2843-2849.

12. Bergdoll MS, Ileal loop fluid accumulation test for diarrhoeal toxins. In: Harshman S (ed) Microbial toxins: tools in enzymology. (Methods in enzymology, vol 165). San Diego, Academic Press. 1988. 306-323.

13. Annapurna E, Sanyal SC. Studies on enteropathogenicity of Aeromonas hydrophila in an experimental model. Indian $J$ Prev Soc Med 1975; 6: 234-237.

14. Stokes EJ, Ridgway GL, Wren MWD. Clinical microbiology, 7th edn. London, Edward Amold. 1993.

15. Anderson ES, Lewis MJ. Drug resistance and its transfer in Salmonella typhimurium. Nature 1965; 206: 579-583.

16. Anderson ES. Origin of transferable drug-resistance factors in the Enterobacteriaceae. BMJ 1965; 2: 1289-1291.

17. Kado CI, Liu S-T. Rapid procedure for detection and isolation of large and small plasmids. J Bacteriol 1981; 145: 13651373.

18. Singh DV, Sanyal SC. Production of haemolysis and its correlation with enterotoxigenicity in Aeromonas spp. $J$ Med Microbiol 1992; 37: 262-267.

19. Chang BJ, Bolton SM. Plasmids and resistance to antimicrobial agents in Aeromonas sobria and Aeromonas hydrophila clinical isolates. Antimicrob Agents Chemother 1987; 31: 1281-1282. 